\title{
A EMPRESA RURAL NO CÓDIGO CIVIL DE 2002: UMA ANÁLISE A PARTIR DE SUA FUNÇÃO SOCIAL E ECONÔMICA
}

\author{
THE RURAL ENTERPRISE IN THE CIVIL CODE OF 2002: AN ANALYSIS \\ FROM ITS SOCIAL AND ECONOMIC
}

\author{
Eduardo Goulart PIMENTA ${ }^{1}$ \\ Luciana Castro BASTOS ${ }^{2}$
}

Artigo recebido em: 13/07/2016

Artigo aprovado em: 06/09/2016

RESUMO: O presente texto tem como objetivo analisar a regulação da empresa rural e do seu agente econômico - o empresário rural - e face dos dispositivos do Código Civil brasileiro. Tal abordagem se faz de importância por dois principais motivos, um de ordem econômica e social, outro eminentemente jurídico. Sob o ponto de vista social e econômico, a relevância do tema está na constatação da grande importância da atividade agrícola e pecuária para

\footnotetext{
1 Possui graduação em Direito pela Universidade Federal de Minas Gerais (1996), mestrado em Direito pela Universidade Federal de Minas Gerais (1998) e doutorado em Direito pela Universidade Federal de Minas Gerais (2003). É Procurador do Estado de Minas Gerais, Professor Adjunto III nos cursos de graduação, especialização, mestrado e doutorado da PUCMINAS, Professor Adjunto de Direito Comercial-Empresarial na Faculdade de Direito da UFMG, professor licenciado dos cursos de Economia e Administração do IBMEC-MG e advogado e consultor em Direito Empresarial no escritório João Bosco Leopoldino Advocacia e Consultoria.

E-mail: goulartpimenta@gmail.com
}

\footnotetext{
${ }^{2}$ Mestranda em Direito Privado pela Pontifícia Universidade Católica de Minas Gerais - PUC Minas. Possui graduação em Direito pela Universidade Iguaçu (2001). Tem experiência na área de Direito, com ênfase em

Direito Empresarial. Pós Graduação Lato Sensu em Direito Civil e

Direito Processual Civil pela Universidade Veiga de Almeida - RJ (2004). Experiência em sala de aula na área jurídica - Curso Preparatório para Concurso.

E-mail: luciana.castro@zipmail.com.br
} 
a economia brasileira, fundamental fonte de riqueza e também de trabalho. Já sob o aspecto eminentemente jurídico, o assunto é relevante dadas as significativas alterações que o Código Civil de 2002 promoveu na regulação do empresário rural, que, em notória excepcionalidade, pode voluntariamente sujeitar-se à regulação pela legislação civil ou empresarial, o que lhe acarreta consequências de relevo abordadas no texto.

PALAVRAS-CHAVE: Empresário rural - Código Civil - direito empresarial.

\begin{abstract}
The present text has as objective to analyze the regulation of the rural enterprise and its economic agent - the rural entrepreneur - with the provisions of the Brazilian Civil Code.Such an approach is of importance for two main reasons, one of economic and social order, another eminently legal. From a social and economic point of view, the relevance of the theme lies in the great importance of agricultural and livestock activity for the Brazilian economy, a fundamental source of wealth and also of work. On the other hand, it is relevant in the light of the significant changes that the Civil Code of 2002 promoted in the regulation of the rural entrepreneur, who, in a notoriously exceptional situation, can voluntarily be subject to regulation by civil or business legislation, which consequences of the text.
\end{abstract}

KEY WORDS: Rural entrepreneur - Civil Code - business law. 


\section{Introdução}

O presente artigo visa abordar, em suas linhas essenciais, o regime jurídico da empresa rural na forma como estabelecido no Código Civil de 2002, passando por algumas notas sobre o Direito Estrangeiro, bem como trazendo dados sobre o Empresário Rural, sua diversa conceituação e controvérsias a respeito do tema.

\section{0 conceito de empresário e a empresa no Código Civil de 2002}

O Direito Comercial precisou, desde suas mais remotas origens, de se apoiar sobre determinado fenômeno jurídico que justificasse a criação de regras especiais apartadas do Direito Comum. Isso porque se trata de um ramo da ciência do Direito surgido, conforme detectam vários estudiosos do assunto, não em função de necessidades de ordem lógica ou científica, mas a partir das exigências das práticas comerciais e daqueles que atuam nesse ramo da atividade humana.

Com o advento do Código de Comércio francês, em 1807, ganhou corpo a noção de atos de comércio. Os diplomas legais passaram a elencar - de forma taxativa ou meramente exemplificativa - determinados atos que, independentemente da circunstância de serem praticados por comerciantes, estariam sob a disciplina do Direito Comercial, pelo simples fato de existir disposição legal a respeito desse enquadramento. É a chamada concepção objetiva deste ramo especial do Direito Privado, oposta àquela anteriormente vigorante (concepção subjetiva), segundo a qual, determinado ato seria regulado pelo Direito Comercial, se fosse praticado por comerciante profissional.

Nosso Código Comercial de 1850 adotou tal posicionamento relegando, entretanto, ao Regulamento $\mathrm{n}^{\circ} 737$ do mesmo ano a tarefa de enumerar, em seu art. 19, aqueles atos apartados da disciplina do Direito Comum.

Porém, com o crescimento da forma monopolística do regime capitalista, foi possível perceber toda a insuficiência dessa noção, como elemento definidor do Direito Comercial, enquanto ramo autônomo do conhecimento jurídico.

Assim foi que, no início do século XX - e especialmente após o Código Civil Italiano de 1942 -, passou-se a invocar a noção de empresa como real e verdadeiro critério distintivo, sobre o qual se apoiariam as regras específicas componentes do ramo especial do Direito Privado. Cumpre ao Direito Comercial, 
dessa forma, a tarefa de regulamentar os chamados "atos de empresa".

O Prof. Ruy de Souza, antigo Catedrático da matéria, foi um dos que recebeu calorosamente a ideia de empresa como elemento caracterizador do objeto das normas de Direito Comercial. Chegou, inclusive, a intitular um dos capítulos de sua obra "O Direito das Empresas - atualização do Direito Comercial"3 de "O Direito Comercial como o Direito das Empresas". É nesse mesmo livro, que encontramos a significativa afirmação de que "a elaboração de um direito comercial fundado na empresa como seu objeto revoluciona, sem dúvida, os processos tradicionais e possui o condão de eliminar os antagonismos teóricos e de minimizar as exceções" ${ }^{\prime 4}$.

Porém, o conceito de empresa apresenta aos estudiosos do Direito um fator complicador de significativa importância.

Trata-se do fato de o conceito de empresa ter origem e inicial desenvolvimento no âmbito da ciência econômica, sendo apenas posteriormente acolhido pela ciência jurídica, como elemento substitutivo da noção de atos de comércio. Informa-nos, Joaquin Garrígues, corroborando a assertiva anterior, que "[...] a palavra empresa é um termo que passou do campo da economia para o direito, tanto nas leis quanto nas obras dos juristas [...] a empresa é um conceito econômico e o conceito jurídico coincide com ele"' 5 . Também François Goré verifica, no direito francês, que "[...] a empresa é uma noção econômica"6.

Apesar disso, passemos à análise do conceito de empresa no Direito Comercial brasileiro, pois, certo ou não, é ele quem assumiu, com a vigência do Código Civil de 2002, a condição de fator de fundamentação científica de todo um grupo de normas jurídicas apartadas do Direito Privado comum.

José Maria Rocha Filho afirma que "economicamente, a empresa é um organismo que se forma pela organização dos fatores de produção, para satisfa-

${ }^{3}$ SOUZA. Rui de. O Direito das Empresas - atualização do Direito Comercial. Livraria Bernardo Álvares Editora, Belo Horizonte, 1959.

${ }^{4}$ SOUZA. Rui de. O Direito..., cit. p. 207.

5 "[...] la palabra empresa es un término que ha pasado desde el campo de la economia al del derecho, tanto en las leyes como en las obras de los juristas (...) la empresa és un concepto económico y el concepto jurídico de ella coincide con él". GARRIGUES. Joaquín. Curso de Derecho Mercantil. Tomo II. Reimpresión de la séptima edición, Editorial Temis, Bogotá, Colômbia, 1987, pg 13. Tradução livre do autor.

6 "l'entreprise est une notion économique". GORÉ. François. Droit des affaires - les commerçants et l'entreprise commerciale. Collection Université Nouvelle, Éditions Montchrestien, Paris, 1973, pg. 129. Tradução livre do autor. 
zer as necessidades das pessoas, para atender às exigências do mercado".

O mesmo autor, ainda, nos diz que "(...) quando se fala em empresa, interessa ao Direito: a) regulamentar a atividade daquele que organizou os fatores de produção para satisfazer necessidades alheias, ou seja, a atividade do empresário; b) proteger as ideias inovadoras, criadoras, surgidas com ou em função do exercício daquela atividade c) disciplinar a formação e a existência daquele conjunto de bens que forma o estabelecimento comercial. Interessa ao Direito, em síntese, a atividade do empresário"7.

Já segundo Celso Barbi Filho, a empresa é "(...) organização profissional de capital e trabalho, destinada à produção, circulação ou prestação lucrativa de bens ou serviços"'s.

Para Fran Martins, "(...) o melhor critério para identificar a empresa comercial é o de considerar como tal aquela em que o empresário se dedica, em caráter profissional, a fazer com que os bens passem de uma pessoa para outra (circulação de bens), praticando esta atividade com intuito de lucro" .

Osmar Brina Corrêa Lima, por sua vez, verifica que "já no campo do Direito Comercial, a empresa é considerada do ponto de vista objetivo, como atividade de uma pessoa, física ou jurídica, que é o empresário" ${ }^{\prime 10}$.

$\mathrm{O}$ anteriormente citado François Goré, por seu turno, refere-se à empresa nos seguintes termos: "[...] é um conjunto de meios humanos e materiais que têm por objeto uma atividade econômica, a produção de um bem ou de um serviço $[\ldots]^{11 " \prime}$.

Apresentadas diversas definições a respeito do que seja a empresa, e verificado que elas apresentam vários pontos de contato entre si, é preciso também mencionar controvérsia de relativa importância prática. Trata-se da definição acerca da natureza jurídica da empresa.

Vários autores de expressão, como Waldírio Bulgarelli, referem-se à

${ }^{7}$ ROCHA FILHO. José Maria. Curso de Direito Comercial. vol. 1 - Parte Geral. Ed. Del Rey, Belo Horizonte, 1994 , p. 61 e 62.

${ }^{8}$ BARBI FILHO. Celso. Contratação entre a sociedade por cotas de responsabilidade limitada e seu próprio administrador. Revista de Direito Mercantil, nº 96, Ed. Revista dos Tribunais, São Paulo, 1994, p. 5.

${ }^{9}$ MARTINS. Fran. Curso de Direito Comercial. 20. ed, Ed. Forense, Rio de Janeiro, 1994, p. 14.

${ }^{10}$ CORRÊA LIMA. Osmar Brina. Sociedades Anônimas - textos e casos. Ed. Forense, Rio de Janeiro, 1991, p. 15.

11 '"...] c'est un ensemble de moyens humains et matériels qui a pour objet une activité économique, la production d'un bien ou d'un service [...]". GORÉ. François. Droit..., cit. pg. 129. Tradução livre do autor. 
empresa como sujeito de direito ${ }^{12}$. Esse movimento encontra respaldo em diferentes tópicos da legislação pátria (Consolidação das Leis do Trabalho, art. $2^{\circ}$, e Constituição Federal de 1988), mas não conseguiu sensibilizar a maioria da doutrina, que, ao menos no âmbito do Direito Comercial, toma a empresa como objeto de direito cuja titularidade cabe ao empresário ${ }^{13}$.

Não há, entretanto, como concordar com a ideia de subjetivação da empresa. Demonstraremos que o correto é, face ao texto do novo Código Civil, tomá-la na acepção de atividade do empresário (individual ou coletivo), este sim sujeito de direitos e de obrigações no mundo jurídico.

Em seu Livro II, o novo Código Civil dedica-se a cuidar do que chama de "Direito de Empresa", o qual nada mais é do que o regime jurídico privado, especialmente elaborado para disciplinar os atos vinculados ao conceito aqui tratado. Assim, o direito positivo brasileiro adota expressa e definitivamente o conceito de empresa como elemento balizador e distintivo entre o campo de incidência das normas de direito privado.

O novo Código, entretanto, preferiu não exibir específica definição de empresa, optando por nos remeter, assim como fez, o Código Italiano de 1942, à caracterização do empresário.

Diz, o caput do art. 966 do novo Código Civil brasileiro: "Considerase empresário quem exerce profissionalmente atividade econômica organizada para a produção ou a circulação de bens ou serviços".

Se empresário é a pessoa que exerce atividade econômica organizada para a produção ou circulação de bens ou serviços, resta claro que, ao contrário do que apregoam os partidários da subjetivação do conceito de empresa, este se refere à atividade e não à pessoa do empresário.

Assim, e a partir das definições acima elencadas, é possível afirmar que empresa, no Direito brasileiro, é qualquer atividade econômica de produção ou distribuição de bens ou serviços com intuito de lucro, realizada e dirigida, mediante a organização de capital e trabalho, pelo empresário.

É verdade que a substituição da teoria dos atos de comércio, consagrada inicialmente no Código Comercial francês de 1807 pela construção em torno dos chamados atos de empresa, contribuirá para o avanço da definição a respeito do

\footnotetext{
${ }^{12}$ BULGARELLI. Waldírio. A teoria jurídica da empresa. Ed. Revista dos Tribunais, São Paulo, 1985, p. 47.

${ }^{13}$ REQUIÃO. Rubens. Curso de Direito Comercial. vol. 1. Ed. Saraiva, São Paulo, 1982. p. 58 e TAVARES PAES. P.R. Curso de Direito Comercial. vol II. Ed. Revista dos Tribunais, São Paulo, 1987, p. 41.
} 
critério distintivo entre as subdivisões do Direito Privado. O conceito de empresa e de empresário trazem para o campo de incidência do regime jurídico comercial uma série de atividades outrora consideradas civis (como a prestação de serviços) e que, há muito, careciam de se sujeitar à mesma disciplina legal dos atos de comércio.

Há que se ressaltar, porém, que o Direito Comercial continuou a regular situações da vida jurídica nem sempre pertencentes a categorias e tipos uniformes entre si em ordenamentos como o italiano, no qual, por via do art. 2.850 do Código de 1942, já se consolidou no Direito Positivo, a teoria da empresa.

Parece-nos clara a supervalorização do poder inerente à ideia de empresa. Temos que a grande contribuição trazida pela adoção desse conceito como fenômeno de fundamentação científica do Direito Comercial é, além da ampliação do campo de incidência do regime jurídico estabelecido por esse ramo, o fato de que, a partir de então, fortalecem-se, ainda mais, as elucubrações em torno de mecanismos jurídico-comerciais voltados à preservação do organismo econômico, em atendimento às exigências vinculadas à concepção de função social da empresa.

Outrora, julgou-se que a empresa, enquanto organização dos meios de produção, era propriedade exclusiva do empresário, que, por sua vez, assumia os riscos e a direção exclusiva do empreendimento.

Entretanto, começaram a surgir manifestações no sentido de que não apenas o interesse e a vontade do empresário devem ser jurídica e economicamente relevantes para o Direito Comercial. Concluiu-se que o organismo empresarial é composto por diferentes categorias funcionais, todas vinculadas à realização da atividade. Segundo François Goré, "uma concepção moderna, ao contrário, vê na empresa um conjunto de três grupos de pessoas (aportadores de capital, quadros de direção e gestão, assalariados) organizados para o exercício de uma atividade econômica"14.

Na doutrina nacional, Alfredo Lamy Filho e José Luis Bulhões Pedreira detectam, de forma aguda e perspicaz, o fato de existirem, na empresa, diferentes grupos de interesses (certamente conflitantes), que formam o que chamam de grupo social ${ }^{15}$. Salientam eles, ainda, que a sociedade empresária é

\footnotetext{
14 "une conception moderne voit au contraire dans l'entreprise un ensemble de trois groupes de personnes (apporteurs de capitaux; cadres de direction et gestion; salariés) organisé en vue de l' exercice d'une activicté économique". GORÉ. François. Droit..., cit. pgs. 130 e 131. Tradução livre do autor.

${ }^{15}$ LAMY FILHO. Alfredo. BULHÕES PEDREIRA. José Luiz. A Lei das S.A. Ed. Renovar. Rio de Janeiro, p. 56 e 57.
} 
apenas um subsistema desse grupo social, ao qual se confere não mais a propriedade absoluta, mas a chefia da empresa, impedindo, dessa forma, que o empresário desconsidere os demais agrupamentos pessoais envolvidos com a atividade comum.

Tal avanço se mostrou de grande significado, pois, como salientamos, o empresário (individual ou coletivo) não mais pode exercer o comando da empresa de forma a atender somente a seus interesses. A ampliação de tal conclusão acabou por levar à ideia de função social da empresa.

\section{Atividades econômicas não empresariais no Código Civil de 2002}

O Direito Privado brasileiro passa a conviver, a partir da entrada em vigor do novo diploma civil, com dois regimes jurídicos distintos, quais sejam: o dedicado à disciplina específica dos atos de empresa e outro, subsidiário, orientado para o regramento dos demais atos privados.

Já afirmamos que o conceito de empresa pode ser obtido a partir da definição de empresário expressa pelo caput do art. 966 do Código Civil de 2002.

Há, entretanto, determinadas atividades econômicas que, embora organizadas para a produção ou circulação de bens ou serviços com intuito lucrativo, foram colocadas fora do âmbito das normas jurídicas reguladoras dos atos de empresa.

Tais atividades econômicas encontram-se no parágrafo único do já mencionado art. 966 do Código Civil de 2002, que diz: "Não se considera empresário quem exerce profissão intelectual, de natureza científica, literária ou artística, ainda com o concurso de auxiliares ou colaboradores, salvo se o exercício da profissão constituir elemento de empresa".

Temos então que qualquer pessoa física ou jurídica que desenvolva profissão intelectual, de natureza científica, literária ou artística terá sua atividade apartada das normas do Direito de Empresa, ainda que pratique tal atividade com intuito lucrativo.

A redação desse parágrafo único parece-nos, com a devida vênia, passível de dúvidas.

Face à literalidade de seu texto, julgamos pertinente a seguinte pergunta: está fora do âmbito das normas do Direito de Empresa, qualquer profissão intelectual ou somente aquelas profissões intelectuais "de natureza científica, literária ou artística"? 
A relevância da pergunta reside na constatação de que há profissões intelectuais que, ao menos diretamente, não têm natureza científica, literária ou artística.

É, por exemplo, o caso dos profissionais liberais: os médicos, os escritórios de contabilidade e engenharia, por exemplo, prestam serviços eminentemente intelectuais com intuito lucrativo, mas que, ao menos diretamente, não apresentam natureza “científica, literária ou artística”. Estariam esses profissionais, desse modo, sujeitos à incidência das normas referentes ao Direito de Empresa ou não, continuando, assim, abarcados pelas normas civis?

Fábio Ulhôa Coelho responde à questão nos seguintes termos: “Exclui do conceito de empresário o exercente de atividade intelectual, de natureza científica, literária ou artísica, mesmo que contem com o concurso de auxiliares ou colaboradores, salvo se constituir o exercício da profissão elemento de empresa (art. 966, parágrafo único). Esse dispositivo alcança, grosso modo, o chamado profissional liberal (advogado, dentista, médico, engenheiro etc.) que apenas se submete ao regime geral da atividade econômica se inserir a sua atividade específica numa organização empresarial (na linguagem normativa, se for 'elemento de empresa' $)^{16 \prime \prime}$.

São estas, dentre outras das dúvidas que, como já ressaltamos no item anterior deste estudo, continuarão a percorrer a mente dos estudiosos, restando demonstrado, em nosso entender, que mesmo a positivação do conceito de empresa não traz a pacificação completa do assunto ora tratado.

\section{A atividade rural e o Direito de Empresa no Código Civil de 2002}

A atividade agropecuária, tradicionalmente, esteve afastada da incidência das normas de Direito Comercial, posto faltar-lhe, à época da consolidação do regime jurídico mercantil, o caráter especulativo e a organização econômica que hoje tornam-se cada vez mais marcantes.

A positivação, pelo Código de 2002, do critério da empresa como elemento definidor do campo de incidência das normas outrora componentes do Direito do Comércio, felizmente, resultou na reparação dessa tradicional e cada vez mais infundada exclusão.

Essa relevante alteração das diretrizes até então vigorantes no direito

${ }^{16}$ COELHO. Fábio Ulhôa. Curso de Direito Comercial. Vol. I. 6. ed. Editora Saraiva. São Paulo, 2002, p. 24. 
pátrio está no art. 971 do Código Civil de 2002. Diz ele: “O empresário, cuja atividade rural constitua sua principal profissão, pode, observadas as formalidades de que tratam o art. 968 e seus parágrafos, requerer inscrição no Registro Público de Empresas Mercantis da respectiva sede, caso em que, depois de inscrito, ficará equiparado, para todos os efeitos, ao empresário sujeito a registro".

Se analisarmos o tema apenas face à literalidade do caput do art. 966, não teremos maiores dúvidas em afirmar que a pessoa (física ou jurídica) que se dedique profissionalmente a atividade agrária é exercente de uma "atividade econômica organizada para a produção ou a circulação de bens ou de serviços", ou seja, é empresário - o chamado empresário rural.

Entretanto, é necessário entender melhor quem é empresário rural e empresa rural, para poder exercer a faculdade de escolha do regime jurídico aplicável.

Reportemos, primeiramente, ao Estatuto da Terra, o qual define de forma restrita a empresa rural como "empreendimento de pessoa física ou jurídica, pública ou privada, que explore econômica e racionalmente imóvel rural, dentro de condição de rendimento econômico... Vetado... da região em que se situe e que explore área mínima agricultável do imóvel segundo padrões fixados, pública e previamente, pelo Poder Executivo. Para esse fim, equiparam-se às áreas cultivadas, as pastagens, as matas naturais e artificiais e as áreas ocupadas com benfeitorias" (Lei 4.504/1964, art.4ํ., VI).

Segundo Alfredo de Assis Gonçalves Neto, "empresário rural é a pessoa natural (a sociedade dedicada à atividade rural é tratada no art. 984) que age de forma organizada e profissionalmente na exploração das riquezas da terra. Quem exerce atividade rural sem organização, para a sua subsistência ou em caráter eventual ou não profissional, não se enquadra no enunciado do art. 966 e, por isso, não se insere no conceito de empresário rural"17.

De acordo com o novo Código, porém, esses profissionais somente se sujeitarão às normas concernentes ao Direito de Empresa, se formalizarem seu registro perante a Junta Comercial de sua sede.

E mais, lendo-se o artigo 971 do CC/2002, de forma literal, podese chegar à seguinte conclusão: o empresário rural não é empresário, mas, se optar por se registrar na Junta Empresarial, que é uma faculdade, continuará

17 GONÇALVES NETO. Alfredo de Assis. Direito de Empresa. 2. Ed. Editora Revista dos Tribunais. São Paulo. 2007. Cap. 1, n. 19, p. 81. 
não sendo empresário, apenas terá tratamento jurídico de empresário (equiparado), sujeitando-se à Falência e às Recuperações Judicial e Extrajudicial. Voltando à análise dos artigos 971 e 984, ambos do CC/2002, pode-se, num primeiro momento, chegar-se à conclusão de que excepcionou a regra quanto à natureza declaratória, vez que a pessoa que exerce a atividade rural, em princípio, não é empresária, mas, se optar pelo registro na Junta Empresarial, passa a se sujeitar à Falência e pode se beneficiar das Recuperações Judicial e Extrajudicial, passando a ser, então, empresária e, por consequência, conferindo caráter constitutivo ao registro.

Equiparar significa que, apesar de não ser propriamente empresária, terá tratamento jurídico, disciplina jurídica de empresário, como se fosse efetivamente, sujeitando-se à insolvência empresarial (falência), bem como podendo se beneficiar dos institutos das Recuperações, sendo esta a principal razão de ocorrer tal equiparação, até porque, o explorador de atividade rural exerce uma atividade produtiva, merecendo, se viável, ter sua atividade recuperada.

A desvantagem, porém, é de que este será obrigado a possuir e manter um sistema de escrituração, nos moldes legais, como livro diário para o lançamento dos fatos a ele relativos e ainda levantar os balanços patrimonial e de resultado econômico ao final de cada exercício financeiro (CC, arts. 1.179 a 1.189), tornando-se dispendiosa e complexa a sua atividade rural, pois necessitará contratar profissional devidamente habilitado (CC, art. 1.177).

Posta assim a questão, fica claro que o próprio rurícola poderá definir qual regime jurídico irá adotar em sua atividade, ou seja, se ele preferir se inscrever no Registro Público de Empresas Mercantis, passará a existir, de forma organizada, uma empresa individual destinada à exploração de atividades rurais.

Conclui-se, portanto, que os empresários rurais passam a representar categoria profissional cujo regime jurídico é definido, não pelo objeto de sua atividade, mas pelo local no qual forem arquivados seus atos constitutivos (Junta Comercial ou Cartório civil).

Assim, tal registro ganha, para esses profissionais, efeito até então desconhecido no Direito brasileiro.

\section{Conclusão}

Dentre as inúmeras e significativas modificações promovidas pela reforma do Direito Privado brasileiro em 2002 está, sem dúvida alguma, a referen- 
te à ampliação do objeto das normas de Direito Comercial.

Se, face ao regime normativo anterior, tais normas se voltavam ao regramento apenas das atividades definidas pelo vetusto Reg. 737, de 1850, a partir da entrada em vigor do novo Código Civil, essas disposições legais passam a cuidar de todas as empresas.

Dentre os setores econômicos que se incluem nessa modificação, está o ligado à exploração profissional e organizada da atividade rural, que hoje pode, dependendo da vontade do sujeito de direito que a ela se dedique, submeter-se às normas do Direito de Empresa.

Sendo assim, é de se dizer que o registro não confere a condição de empresário, sequer nas hipóteses previstas nos artigos 971 e 984, ambos do CC/2002, mas nada impede que a pessoa que explore atividade rural possa ser tratada como devedora da Lei $\mathrm{n}^{\circ} 11.101 / 2005$, bastando optar por se registrar na Junta Empresarial.

\section{Referências}

BARBI FILHO. Celso. Contratação entre a sociedade por cotas de responsabilidade limitada e seu próprio administrador. Revista de Direito Mercantil, $\mathrm{n}^{\circ}$ 96. Ed. Revista dos Tribunais, São Paulo, 1994.

BULGARELLI. Waldírio. A teoria jurídica da empresa. Ed. Revista dos Tribunais, São Paulo, 1985.

COELHO. Fábio Ulhôa. Curso de Direito Comercial. Vol. I. 6. ed. Editora Saraiva. São Paulo. 2002.

CORRÊA LIMA. Osmar Brina. Sociedades Anônimas - textos e casos. Ed. Forense, Rio de Janeiro, 1991.

GARRIGUES. Joaquín. Curso de Derecho Mercantil. Tomo II. Reimpresión de la séptima edición, Editorial Temis, Bogotá, Colômbia, 1987.

GONÇALVES NETO. Alfredo de Assis. Direito de Empresa 2.ed. Editora Revista dos Tribunais. São Paulo. 2007. 
GORÉ. François. Droit des affaires - les commerçants et l'entreprise commerciale. Collection Université Nouvelle, Éditions Montchrestien, Paris, 1973.

LAMY FILHO. Alfredo, e BULHÕES PEDREIRA. José Luis. Lei das S.A. Ed. Renovar, Rio de Janeiro, 1992.

MARTINS. Fran. Curso de Direito Comercial. 20. ed. Ed. Forense, Rio de Janeiro, 1994.

REQUIÃO. Rubens. Curso de Direito Comercial. vol. 1. Ed. Saraiva, São Paulo, 1982.

ROCHA FILHO. José Maria. Curso de Direito Comercial. vol. 1 - Parte Geral. Ed. Del Rey, Belo Horizonte, 1994.

SOUZA. Rui de. O Direito das Empresas - atualização do Direito Comercial. Livraria Bernardo Álvares Editora, Belo Horizonte, 1959.

TAVARES PAES. P.R. Curso de Direito Comercial. vol II. Ed. Revista dos Tribunais, São Paulo, 1987. 2002. 